\title{
Application of Polygraph in Concealed Information Test
}

\author{
Di Wang \\ Department of Psychology, Hangzhou Normal University, Hangzhou, China \\ Email: 17806096362@163.com
}

How to cite this paper: Wang, D. (2020) Application of Polygraph in Concealed Information Test. Open Access Library Journal, 7: e6804.

https://doi.org/10.4236/oalib.1106804

Received: September 8, 2020

Accepted: September 22, 2020

Published: September 25, 2020

Copyright $\odot 2020$ by author(s) and Open Access Library Inc.

This work is licensed under the Creative Commons Attribution International License (CC BY 4.0).

http://creativecommons.org/licenses/by/4.0/ (c) (i)

\begin{abstract}
The polygraph-based Concealed Information Test (CIT) uses psychophysiological measures to determine whether there are crime-related information in suspects' memory. This study explores the physiological indicators used in polygraph-based CIT and their effectiveness. Furthermore, we introduce the theoretical basis of physiological-based CIT. It is pointed out that further researches should thoroughly explore the different physiological responses and psychological process in the CIT paradigm and strengthen the comprehensive research on different psychological indicators.
\end{abstract}

\section{Subject Areas \\ Criminology, Psychology}

\section{Keywords}

Polygraph, Concealed Information Test, Psychological Measurement

\section{Psychophysiological Methods of Deception Detection}

The physiological detection methods can be roughly divided into two categories: 1) a direct measure of deception, which directly asks the subject questions related to the case, such as "Did you kill XX?" The physiological responses of the subjects were also recorded. 2) Indirect lie detection by measuring concealed information, such as "Is the murder weapon a knife? a gun?" The first kind of polygraph detection method is called Control Questions Technique (CQT) and is widely used in the judicial field. The second type is called the Guilty Knowledge Test (GKT), also known as the Concealed Information Test (CIT).

\subsection{The Application and Principle of CQT in Polygraph}

Comparison Question test or Control Question Test (CQT) (Raskin, 1987 [1]; 
Reid, 1947 [2]) is the most commonly used paradigm in polygraph, and it is widely used in many law enforcement agencies, especially in North America and Israel (Meijer \& Verschuere, 2017) [3]. The participants were asked a series of questions and their physiological responses were recorded. Three types of questions are usually presented: 1) Relevant questions usually involve questions that require investigation, such as "did you kill XX on November 3rd?" The subjects' physiological responses to the question were compared with the control question. 2) The control question is usually irrelevant to the case under investigation but involves the subject's previous negligent behavior, which usually does not conform to the norm and involves the subject's moral qualities, such as "Have you ever taken something that does not belong to you early in your life?" Subjects were asked to give negative answers to these questions. 3) Irrelevant questions are completely neutral questions, usually describing a fact such as "Are you sitting in your chair right now?" All questions are usually repeated three or four times (Gershon Ben-Shakhar \& Eitan Elaad, 2002) [4]. Through pretest interviews, innocent people are convinced of the scientific and accurate nature of the test, so that they will not be nervous because they worry about making mistakes in the test. Polygraph using CQT usually compares participants' physiological responses to relevant questions and control questions. The theoretical assumption is that relevant questions are more threatening to the criminals and therefore generate a stronger physiological response, while innocent people are unfamiliar with relevant questions, control questions are more threatening to them and induce a greater physiological response. However, this paradigm has been criticized by scholars for its lack of scientific theoretical basis and improper criteria will increase the false positive rate (Eitan Elaad, 2003 [5]; Lykken, 1974 [6]; Meijer \& Verschuere, 2014 [7]).

\subsection{Orienting Response and Inhibition Theory}

In polygraph-based GKT, physiological indicators such as skin conductance response, heart rate and respiration are usually used. When relevant items were presented, the suspects usually exhibited increased skin conductance response, decreased heart rate and shorter respiration line length (RLL) (G. Ben-Shakhar, 1977 [8]; Lieblich \& Ben Shakhar, 1970 [9]; Lykken, 1974 [6]). This was commonly referred to as the CIT effect. In the past, this was usually explained by the orienting response, but recent studies have shown that the skin conductance response reflected the orienting response, while the heart rate and respiration reflected the inhibition theory (W. Ambach, R. Stark, M. Peper, \& D. Vaitl, 2008 [10]; W. Ambach, R. Stark, M. Peper, \& D. J. I. J. o. P. Vaitl, 2008 [11]; Klein Selle, Verschuere, Kindt, Meijer, \& Ben-Shakhar, 2016 [12], 2017 [13]; Matsuda, Nittono, \& Ogawa, 2013 [14]; B. Verschuere, Crombez, Koster, Van Bockstaele, \& De Clercq, 2007 [15]). The truth was automatically activated. Therefore, individuals with deceptive motives were confronted with conflicts, that was, they recognized crime-related items but through verbal response or key press response suggested that they didn't know relevant items. Individuals resolve con- 
flicts by suppressing real reactions. Executive function allows individuals to deliberately suppress superiority or spontaneous reactions. In CIT, inhibition can be manifested as response inhibition and arousal inhibition. Response inhibition is manifested at the behavioral level, that is, not knowing crime-related items. Arousal inhibition is manifested as the inhibition of physiological arousal of relevant items to avoid the detection of concealed information. In order to suppress the reaction to relevant items, some effort was needed, but this will cause the typical CIT effect.

\section{The History of Polygraph and the Physiological Indicators Commonly Used in Polygraph}

\subsection{History of Polygraph}

The polygraph originated from Latin, "poly" means multiple or many, "graph" means writing, and recording different physiological parameters with a recording device (Synnott, Dietzel, \& Ioannou, 2015) [16]. In the past, polygraphs used multiple pens to record physiological signals on a long roll of paper. Now they are composed of a small amplifier/digital processor and a laptop. The first polygraph was produced in 1921. California police and psychologist John Larson (John Larson) designed an instrument that can continuously measure blood pressure, heart rate, and respiratory rate. Keller created the first procedure "Relevant/Irrelevant Questions", which based on psychological measurement, and added the skin conductance response channel to the polygraph in 1938. Modern computerized polygraph include sensors, converters and processors. Sensors include skin conductance sensors, respiration sensors, pulse/blood pressure sensors and motion sensors. The converter filters and amplifies the analog signals collected by the sensors and then converts them into digital signals. The processor performs various processing on the digital signals. This digital and electronic trend makes use of the acquisition, filtering, and amplifying technology of ana$\log$ electronic technology to make the operation of the polygraph technology easier, faster and make the result more accurate(Staunton \& Hammond, 2011 [17]; Synnott et al., 2015 [15]).

\subsection{Psychological Indicators Used in Polygraph-Based CIT}

The polygraph usually measures the activity of autonomic nerve response such as skin conductance response, heart rate and respiration to achieve the purpose of detecting concealed information. The hypothesis of polygraph-based CIT is that lying will change the average level of skin conductance response, heart rate, respiration and other indicators (Staunton \& Hammond, 2011) [17]. In polygraph-based CIT, the suspects usually exhibited physiological reactions such as increased skin conductance response, decreased heart rate and shorter respiration line length, which is called the CIT effect.

\subsubsection{Skin Conductance Response (SCR)}

Since the systematic study of CIT, a large number of studies have shown that 
skin resistance amplitude or skin conductance response for irrelevant items was greater than neutral items (Horneman \& O’Gorman, 1985 [18]; Waid, Orne, \& Wilson, 1979 [19]). The electrical resistance and electrical conductivity of the skin largely depended on the activity of the sweat-producing endocrine glands, which were controlled by the sympathetic nervous system. Since the endocrine glands have acetylcholine as a postganglionic neurotransmitter, they are not affected by epinephrine or norepinephrine level fluctuations in the blood (Synnott et al., 2015) [15]. Lykken (1959) used a simulated crime procedure and only used single physiological indicator of skin conductance response for the detection of concealed information. The results showed that $88 \%$ of suspects were correctly identified, and no innocents are identified as suspects. In his subsequent research, he used autobiography-based CIT to detect concealed information, and 20 subjects were correctly identified as criminals. Due to its large response range and high sensitivity, skin conductance response was not easy to be controlled by the individual, so it has been widely used in the field of polygraph-based CIT.

\subsubsection{Heart Rate, Blood Pressure and Pulse}

The heart rate, pulse and blood pressure in the human circulatory system are three closely related physiological parameters, and the changes of the three are affected by the intensity and amplitude of myocardial activity as well as the psychological state. For example, when the individual encounters a dangerous situation, the heart rate increases, pulse beats increase, and blood pressure rises; when the individual confirms safety, cardiovascular activities return to normal levels. The hypothalamus plays an important role in the regulation of cardiovascular activities. It can not only regulate the internal organs of individuals, but also play an important role in the regulation of emotions such as anger and fear. Therefore, changes in mental state will affect the activities of the cardiovascular system, thereby affecting physiological changes such as heart rate, blood pressure and pulse. When faced with crime-related problems, individuals may experience increased heart rate and blood pressure due to psychological stress and other factors.

\subsubsection{Respiratory Response}

Respiration is the process of gas exchange between the body and the external environment. In CIT, respiratory changes are usually measured by recording changes in the volume of the chest and abdomen. The breathing rate of an individual varies greatly in different states, which can reach 16 - 20 times per minute in a calm state, and more than 40 times in an angry mood. When an individual is anxious or shocked, the breathing rate increases but the breathing depth basically tends to be normal (Skaggs, 1930). Timm (1982) recommends measuring the total length of the breath during a fixed time after the stimulus is presented, such as 10 or 15 seconds(Timm, 1982) [20]. In this way, a comprehensive estimate of respiratory activity can be obtained, which is called respiratory line length (RLL). Studies have shown that in CIT, compared with innocents, the suspects' 
respiratory line length became shorter when presenting crime-related information (Bruno Verschuere, Crombez, Degrootte, \& Rosseel, 2010 [21]; B. Verschuere, Crombez, Koster, \& De Clercq, 2007 [22]).

\section{The Limitation of CIT and Solution}

Countermeasures, as the name suggests, are that suspects deliberately used some techniques to change his or her physical response to avoid being detected as lying. In practical applications, suspects have stronger incentives to evade punishment, so they were more likely to adopt countermeasures. Countermeasures will increase the false-negative rate, which means that the offender was identified as innocent. Because these countermeasures could make irrelevant items become meaningful and produce physiological response similar to that of related items (G. Ben-Shakhar \& K. Dolev, 1996 [23]; C. R. Honts, M. K. Devitt, M. Winbush, \& J. C Kircher, 1996 [24]) and irrelevant and relevant items can't be distinguished. Studies have shown that when criminal information was presented, it was the most effective countermeasures for suspects to take physical or psychological measures to improve the physiological response (Gershon Ben-Shakhar \& Karmela Dolev, 1996 [23]; E. Elaad \& Ben-Shakhar, 1991 [25]; C. R Honts, M. K Devitt, M Winbush, \& J. C Kircher, 1996 [24]). Physical countermeasures included biting the tongue to increase pain. Psychological countermeasures included recalling exciting or other emotional memories when presented irrelevant items. Psychological countermeasures are more difficult to detect during the test and therefore more harmful. Researches by Ben-Shakhar and Dolev and Honts et al. (1996) showed that when psychological countermeasures were used, it greatly reduced the accuracy of skin conductance response in CIT. But these countermeasures had little effect on respiration.

Some studies have shown that compared with other physiological indicators, the accuracy of polygraph-based CIT was the highest. In addition, the combination of multiple physiological indicators was also important to improve the accuracy of polygraph-based CIT, especially when the combination of the two physiological indicators of skin galvanic and respiration produced the highest level of accuracy (G. Ben-Shakhar \& K. Dolev, 1996 [23]; G. Ben-Shakhar \& E. Elaad, 2002 [4]; G. Ben-Shakhar, Gronau, \& Elaad, 1999 [26]; E. Elaad \& Ben-Shakhar, 1997 [27]). Perhaps it was because the skin conductance response mainly reflected the orienting response and the respiration mainly reflected the inhibition process of the individual. At the same time, using a combination of multiple indicators for polygraph detection could also reduce the impact of countermeasures on the accuracy of polygraph-based CIT (G. Ben-Shakhar, 2012) [28].

\section{Evaluation and Outlook}

In the polygraph-based CIT, the physiological indicators, such as skin conductance response, respiration, and heart rate, can be easily recorded, and the rec- 
orded data can be objectively analyzed. In terms of practicality and effectiveness, every new technology designed to detect concealed information should be compared with this standard. But there are some problems in researches about CIT should be paid attention to.

First, in the past, only a single directed response was used to explain the CIT effect that occurred during the polygraph detection process. However, Klein Selle et al. proposed that the skin conductance response in the CIT polygraph paradigm mainly reflects the orienting theory, that is, for criminal suspects, relevant items would cause the orienting response, while heart rate and respiratory mainly reflect the theory of inhibition. When crime-related information was presented, the offender would intentionally inhibit physiological response, but this inhibition will lead to the CIT effect (klein Selle et al., 2016) [12]. Obviously, as the research on the CIT paradigm continues to deepen, a single theory cannot effectively explain the diversified reactions of the subject during the polygraph test. Therefore, through continuous research, new theories may be developed to explain the subject's physiological response and to better guide the development of the CIT paradigm.

\section{Conflicts of Interest}

The author declares no conflicts of interest regarding the publication of this paper.

\section{References}

[1] Raskin, D.C. (1987) An Investigation of the Guilty Knowledge Test Polygraph Examination. Canadian Journal of Behavioural Sciencel Revue Canadienne des Sciences du Comportement, 19, 389-404. https://doi.org/10.1037/h0079999

[2] Reid, J.E. (1947) A Revised Questioning Technique in Liedetection Tests. Journal of Criminal Law and Criminology, 37, 542-547. https://doi.org/10.2307/1138979

[3] Meijer, E.H. and Verschuere, B. (2017) Deception Detection Based on Neuroimaging: Better than the Polygraph? Journal of Forensic Radiology and Imaging, 8, 17-21. https://doi.org/10.1016/j.jofri.2017.03.003

[4] Ben-Shakhar, G. and Elaad, E. (2002) Effects of Questions' Repetition and Variation on the Efficiency of the Guilty Knowledge Test: A Reexamination. Journal of Applied Psychology, 87, 972-977. https://doi.org/10.1037/0021-9010.87.5.972

[5] Elaad, E. (2003) Is the Inference Rule of the "Control Question Polygraph Technique" Plausible? Psychology, Crime \& Law, 9, 37-47. https://doi.org/10.1080/10683160308143

[6] Lykken, D.T. (1974) Psychology and the Lie Detector Industry. American Psychologist, 29, 725-739. https://doi.org/10.1037/h0037441

[7] Meijer, E.H. and Verschuere, B. (2014) The Polygraph. In: Granhag, P.A., Vrij, A. and Verschuere, B., Eds., Detecting Deception: Current Challenges and Cognitive Approaches, John Wiley \& Sons, Ltd., Hoboken, 59-80. https://doi.org/10.1002/9781118510001.ch3

[8] Ben-Shakhar, G. (1977) A Further Study on the Dichotomization Theory in Detection of Information. Psychophysiology, 14, 408-441. 
https://doi.org/10.1111/j.1469-8986.1977.tb02974.x

[9] Lieblich, I., Kugelmass, S. and Ben Shakhar, G. (1970) Efficiency of GSR Detection of Information as a Function of Stimulus Set Size. Psychophysiology, 6, 601-608. https://doi.org/10.1111/j.1469-8986.1970.tb02249.x

[10] Ambach, W., Stark, R., Peper, M. and Vaitl, D. (2008) An Interfering Go/No-Go Task Does Not Affect Accuracy in a Concealed Information Test. International Journal of Psychophysiology, 68, 6-16. https://doi.org/10.1016/j.ijpsycho.2007.11.004

[11] Ambach, W., Stark, R., Peper, M. and Vaitl, D. (2008) Separating Deceptive and Orienting Components in a Concealed Information Test. International Journal of Psychophysiology, 70, 95-104. https://doi.org/10.1016/j.ijpsycho.2008.07.002

[12] Klein Selle, N., Verschuere, B., Kindt, M., Meijer, E. and Ben-Shakhar, G. (2016) Orienting versus Inhibition in the Concealed Information Test: Different Cognitive Processes Drive Different Physiological Measures. Psychophysiology, 53, 579-590. https://doi.org/10.1111/psyp.12583

[13] Klein Selle, N., Verschuere, B., Kindt, M., Meijer, E. and Ben-Shakhar, G. (2017) Unraveling the Roles of Orienting and Inhibition in the Concealed Information Test. Psychophysiology, 54, 628-639. https://doi.org/10.1111/psyp.12825

[14] Matsuda, I., Nittono, H. and Ogawa, T. (2013) Identifying Concealment-Related Responses in the Concealed Information Test. Psychophysiology, 50, 617-626. https://doi.org/10.1111/psyp.12046

[15] Verschuere, B., Crombez, G., Koster, E.H., Van Bockstaele, B. and De Clercq, A. (2007) Startling Secrets: Startle Eye Blink Modulation by Concealed Crime Information. Biol Psychol, 76, 52-60. https://doi.org/10.1016/j.biopsycho.2007.06.001

[16] Synnott, J., Dietzel, D. and Ioannou, M. (2015) A Review of the Polygraph: History, Methodology and Current Status. Crime Psychology Review, 1, 59-83. https://doi.org/10.1080/23744006.2015.1060080

[17] Staunton, C. and Hammond, S. (2011) An Investigation of the Guilty Knowledge Test Polygraph Examination. Journal of Criminal Psychology, 1, 1-14. https://doi.org/10.1108/20093829201100001

[18] Horneman, C.J. and O'Gorman, J.G. (1985) Detectability in the Card Test as a Function of the Subject's Verbal Response. Psychophysiology, 22, 330-333. https://doi.org/10.1111/j.1469-8986.1985.tb01609.x

[19] Waid, W.M., Orne, M.T. and Wilson, S.K. (1979) Effects of Level of Socialization on Electrodermal Detection of Deception. Psychophysiology, 16, 15-22. https://doi.org/10.1111/j.1469-8986.1979.tb01430.x

[20] Timm, H.W. (1982) Analyzing Deception from Respiratory Patterns. Journal of Police Science and Administration, 10, 47-51.

[21] Verschuere, B., Crombez, G., Degrootte, T. and Rosseel, Y. (2010) Detecting Concealed Information with Reaction Times: Validity and Comparison with the Polygraph. Applied Cognitive Psychology, 24, 991-1002. https://doi.org/10.1002/acp.1601

[22] Verschuere, B., Crombez, G., Koster, E.H. and De Clercq, A. (2007) Antisociality, Underarousal and the Validity of the Concealed Information Polygraph Test. Biological Psychology, 74, 309-318. https://doi.org/10.1016/j.biopsycho.2006.08.002

[23] Ben-Shakhar, G. and Dolev, K. (1996) Psychophysiological Detection through the Guilty Knowledge Technique: Effects of Mental Countermeasures. Journal of Applied Psychology, 81, 273-281. https://doi.org/10.1037/0021-9010.81.3.273 
[24] Honts, C.R., Devitt, M.K., Winbush, M. and Kircher, J.C. (1996) Mental and Physical Countermeasures Reduce the Accuracy of the Concealed Knowledge Test. Psychophysiology, 33, 84-92. https://doi.org/10.1111/j.1469-8986.1996.tb02111.x

[25] Elaad, E. and Ben-Shakhar, G. (1991) Effects of Mental Countermeasures on Psychophysiological Detection in the Guilty Knowledge Test. International Journal of Psychophysiology, 11, 99-108. https://doi.org/10.1016/0167-8760(91)90001-E

[26] Ben-Shakhar, G., Gronau, N. and Elaad, E. (1999) Leakage of Relevant Information to Innocent Examinees in the GKT: An Attempt to Reduce False-Positive Outcomes by Introducing Target Stimuli. Journal of Applied Psychology, 84, 651-660.

https://doi.org/10.1037/0021-9010.84.5.651

[27] Elaad, E. and Ben-Shakhar, G. (1997) Effects of Item Repetitions and Variations on the Efficiency of the Guilty Knowledge Test. Psychophysiology, 34, 587-596.

https://doi.org/10.1111/j.1469-8986.1997.tb01745.x

[28] Ben-Shakhar, G. (2012) Current Research and Potential Applications of the Concealed Information Test: An Overview. Frontiers in Psychology, 3, 342.

https://doi.org/10.3389/fpsyg.2012.00342 